\title{
Analysis of the factors of sustainable development of ecosystems in the territories of the North
}

\author{
Nina Ilysheva ${ }^{1}$, Elena Karanina, ${ }^{2, *}$, and Elena Baldesku ${ }^{3}$ \\ ${ }^{1}$ Ural Federal University named after the First President of Russia B.N. Yeltsin, Mira Str., 19, 620002 \\ Ekaterinburg, Russia \\ ${ }^{2}$ Vyatka State University, Moskovskaya St., 36,610000 Kirov, Russia \\ ${ }^{3}$ Project Office for the Development of the Arctic (PORA), Zoologicheskaya Str., 26/2, 123056 \\ Moscow, Russia
}

\begin{abstract}
The article considers the problem of achieving sustainable development. The purpose of this study is to identify the interconnection between the components of sustainable development, taking into account the involvement of indigenous peoples in the protection of the environment. In the context of climate change, the process of achieving sustainable development is becoming more complicated. Indigenous peoples are the first to feel the effects of climate change and play an important role in the environmental monitoring of their places of residence. The environment is the basis of life for indigenous peoples, and bioresources are the main source of food supply. Over time, the value of bioresources will increase, and therefore, economic development cannot be considered in isolation. It is assumed that the stability components are interconnected and affect each other. To identify this interconnection, a correlation model was developed. The model is based on statistical methods and allows us to determine the close interconnection between economic development and its environmental footprint in the context of climate change. The developed correlation model can be used by a wide range of state-owned companies, and the general principles for constructing this model can be used by companies of different industries.
\end{abstract}

\section{Introduction}

In the last decade, the attention of society has been focused on the scientific search for options for creating a working model of the coexistence of man, technology and nature. The constantly growing demands of the «consumer society» are accompanied by a negative impact on the environment. The social goals of the development of the indigenous peoples of the North (preservation of traditions, language) are replaced by production tasks. In connection with the active economic development of the Arctic, the economy begins to increasingly feel the negative consequences of extensive growth in the form of a decrease in the resource base, deterioration of the health of the indigenous population and an

${ }^{*}$ Corresponding author: kafinanc@yandex.ru 
increase in the proportion of ecosystems incapable of self-healing [1]. The concept of sustainable development focuses on the interconnection of three main components: economic, social and environmental. Achieving harmony between these components is called sustainable development.

The concept of «sustainable development» was formulated as a stable socio-economic development that meets the needs of the current generation, without threatening the next generation [2].

Some researchers determine the practical possibility of achieving sustainable development through the transition to a «green» economy [3]. The green economy is characterized by low consumption of fossil fuels and the associated low environmental impact [4].

The Government of the Russian Federation has developed a «Strategy for the long-term development of the Russian Federation with low greenhouse gas emissions until 2050», the main goal of which is the transition to a trajectory of economic development with low carbon emissions - a «green» economy. Mitigation of climate change can be achieved by accounting for and reducing $\mathrm{CO} 2$ emissions into the atmosphere by all countries, which requires international agreements.

5 December 2019 the Global Carbon Project published the global carbon budget and carbon emissions by country [5]. Using the conversion factor ( 1 billion tons of $\mathrm{C}=3.664$ billion tons of $\mathrm{CO} 2$ ), $\mathrm{C}$ emissions can be converted to $\mathrm{CO} 2$ emissions.

Taking into account the transboundary movement of atmospheric masses, it is worth noting that China, the United States, India and Russia make the largest contribution to global carbon dioxide emissions [6].

When fossil fuels are burned, greenhouse gases are emitted that lead to global warming [7]. Energy accounts for more than 90 percent of $\mathrm{CO} 2$ emissions and 75 percent of total greenhouse gas emissions, according to research by the Intergovernmental Panel on Climate Change (IPCC). The northern regions are the main consumers of energy resources due to the harsh climatic conditions and the active development of the oil and gas industry.

The mechanism for creating the greenhouse effect is as follows: the sun's energy penetrates the atmosphere, is absorbed by the earth's surface and turns into thermal energy. The accumulated greenhouse gases absorb this energy, acquiring a high temperature, and thereby heat the atmosphere. Consequently, the more greenhouse gases in the atmosphere, the more thermal energy will accumulate, which will lead to warming, the so-called «greenhouse effect». The consequences of the greenhouse effect include ecosystem disruption, natural disasters (drought, flooding) and risks to society [8].

For the northern territories, taking into account the specifics of northern ecosystems, their vulnerability, it can be assumed that the main impact of climate change consequences will be on bioresources [9]. Bioresources are the main source of food supply for indigenous peoples [10]. Indigenous peoples are among the first to feel the effects of climate change because their culture and way of life are closely linked to the environment and natural resources.

According to WWF estimates, in 10 years, changes will occur in $30 \%$ of the Arctic ecosystems where indigenous peoples live. Among the changes that will occur, an earlier arrival of spring and the melting of the snow cover, a later freeze-up on rivers and at sea, the replacement of some plant species with others. Large ungulates can starve due to the lack of vegetation or the appearance of an ice crust on top of it in spring, while marine mammals, on the contrary, will not have enough ice cover to hunt far from the coast. Thus, indigenous peoples become an important link in the environmental monitoring system and play a leading role in implementing the Sustainable Development Goals in the face of climate change. 
With the development of the technological process, sustainable development and its research require a standardized approach from us, environmental and economic indicators are closely interrelated and affect each other. This requires a single indicator of sustainability, in connection with which there are good questions: is it possible to select individual indicators of sustainability and identify their interconnection with other factors? How do you do it?

\section{Method of statistical correlation}

The answers to the above questions are supposed to be positive. To confirm this opinion, based on statistical methods, a correlation model was developed. The model includes quantifiable variables and reveals the interconnection between economic progress and its ecological footprint. Figure 1 shows the structure of the model.

The originality of the model lies in the fact that it takes into account the specifics of the northern region, the system of indicators is developed taking into account their significance for the indigenous peoples. For ease of use, the indicators are aggregated into the ecological development index and the economic development index, between which the interconnection is revealed. The existing models have a different focus and offer appropriate statistical methods, for example, the method of pair correlation of individual indicators, the integral index of sustainable development and its interconnection with the indices of structural changes, a macromodel based on the construction of equations.

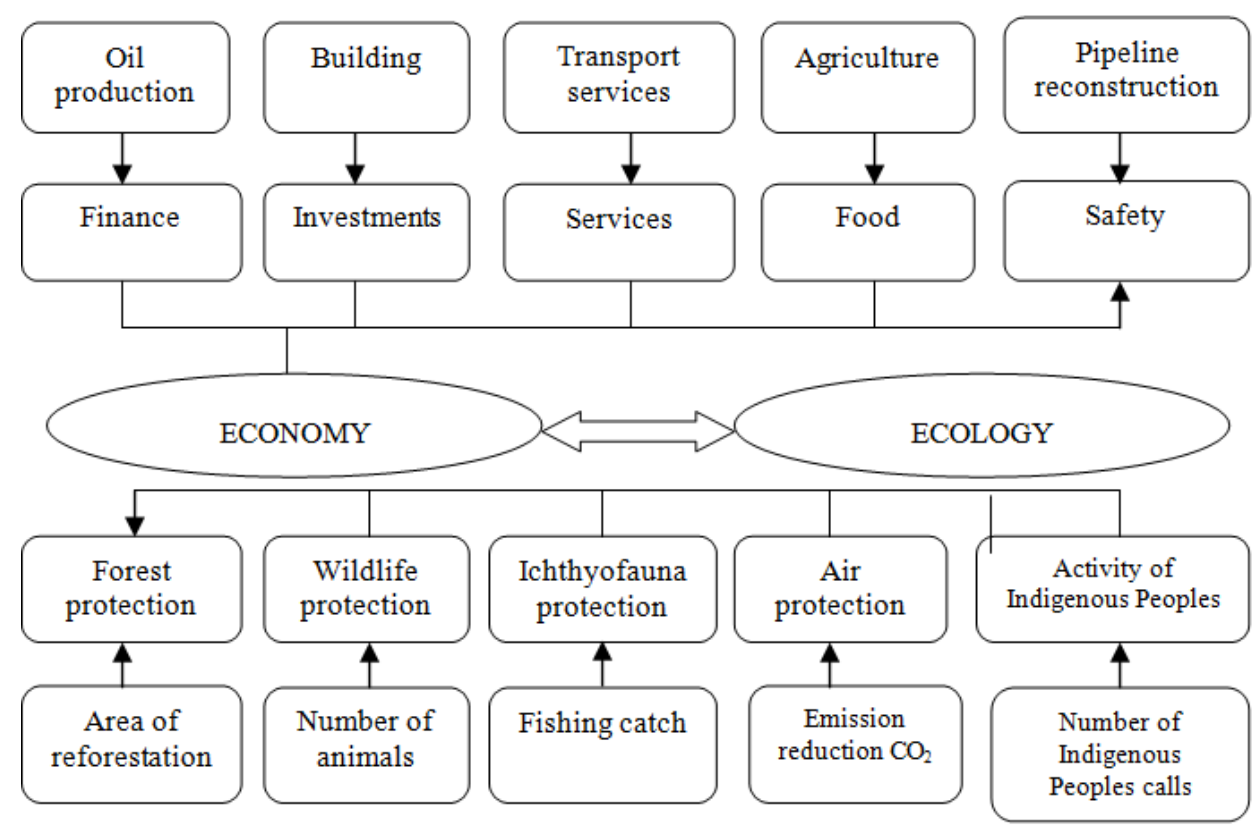

Fig. 2. Structure of the model

The ecological part of the model is divided into 5 components: forest protection, wildlife protection, ichthyofauna protection, air protection and activity of indigenous peoples in environmental protection.

Forest protection. Forests play a crucial role in mitigating the effects of climate change not only due to the absorption of greenhouse gases, but also by creating favorable conditions for life: they regulate the water regime, improve soil conditions and create migration corridors for plants and animals. The reforestation indicator (ha) is used. 
Wildlife protection. Climate change is affecting animals. By the number and migration routes of animals, one can judge the consequences of climate change. The indicator of the number of animals (thousand individuals) is used. The indicator can be used as an indicator of climate change.

Ichthyofauna protection. As a result of climatic changes, fluctuations of many hydrometeorological factors occur, which, in turn, affects the species composition of hydrobionts, the productivity of individual components of hydroecosystems, and the physiological and biochemical state of individual individuals. The catch indicator is used (tonnes). The indicator can be used as an indicator of climate change.

Air protection. The burning of fossil fuels leads to the release of $\mathrm{CO} 2$, which accumulates in the atmosphere and has a warming effect on the climate. Reducing $\mathrm{CO} 2$ emissions into the atmosphere is the main indicator of reducing climate impact (tonnes).

Indigenous participation in environmental protection. Monitoring and timely decisionmaking are facilitated by monitoring and timely decision-making, which is ensured by the indigenous peoples, who instantly react and notify the competent authorities about violations of the law (number of complaints).

The economy is also represented by 5 components: financial, investment, service, food and technological.

Oil production. Income from oil production is the main indicator of the financial success of the region.

Building. Investment activity related to construction was taken as a proxy parameter, since investment activity is related to the present and the future, thereby representing the strategy of the region.

Transport services. The volume of transport services rendered is largely related to servicing the oil and gas complex. Their growth shows economic activity in this particular industry.

Agriculture. The Khanty-Mansiysk Autonomous District - Yugra belongs to the territory of the Far North and areas equated to it, where the production of agricultural products without state support is not profitable. Therefore, economic growth in agriculture indicates an increase in government interest.

Pipeline safety (pipeline reconstruction). The environmental safety of an oil and gas producing region is often determined by the accident rate at industrial facilities. The pipeline reconstruction indicator $(\mathrm{km})$ is used.

In order to determine the interconnection between environmental and economic data, it is necessary to integrate indicators into one unit of measurement. This is difficult to do, since the economy is represented in monetary units, while ecology uses its own units of measurement. For a simple regression, different units will not be a problem, as this will not affect the result. The author's correlation model assumes aggregation of indicators into one index and it is not logical to use different units of measurement (ha, tons, units) in the calculation. To obtain a common unit of measurement, statistical data were taken in the form of natural logarithms [11]. Thus, the formula for characterizing the ecological development of the region is as follows:

ISDecol $=0,2 * \operatorname{Ln}(A)+0,2 * \operatorname{Ln}(F)+0,1 * \operatorname{Ln}(R)+0,1 * \operatorname{Ln}(C I P)-0,4 * \operatorname{Ln}(E C O 2)$,

ISDecol - an index of sustainable environmental development;

A - number of animals, thousand individuals/year;

$\mathrm{F}$ - catch finfish, tonnes/year;

$\mathrm{R}$ - area of reforestation, ha/year;

CIP- number of calls of indigenous peoples, pieces;

$\mathrm{ECO}_{2}$ - volume of $\mathrm{CO}_{2}$ emissions into the atmosphere, tons/year. 
It is assumed that each environmental index indicator has its own significance, which is expressed in different weights of the variables. As a rule, $\mathrm{CO} 2$ emissions are of more global importance in the problem of climate change than the number of animals, this variable was given the greatest weight.

Production and technological indicators in the economic part should be converted into natural logarithms. The remaining three indicators - investment, servicing and food - are presented in the monetary unit of measurement, they could have remained the same, but, nevertheless, the volume of industrial production and technology is as important as investments and have an impact on the region's income in the long run.

Thus, the formula for characterizing the economic development of the region is as follows:

ISDecon $=0,3 * \operatorname{Ln}(O P)+0,2 * \operatorname{Ln}(C)+0,2 * \operatorname{Ln}(T S)+0,1 * \operatorname{Ln}(A)+0,2 * \operatorname{Ln}(R P)$,

ISDecon - index of sustainable economic development;

OP - production component (oil production);

$\mathrm{C}$ - investment component (construction);

TS - serving component (transport services);

A - food component (agriculture);

$\mathrm{RP}$ - technological component (reconstruction of pipelines).

As well as in the index of ecological development, each factor has its own degree of significance [12]. The production component is the stronger side of the region's economic development, while agriculture is less profitable, so the oil production component was given the most weight.

The Khanty-Mansiysk Autonomous District - Ugra was chosen as the object of correlation research. To form the information base of the correlation analysis, we used the statistical data of the Reports on the environmental situation in the Khanty-Mansiysk Autonomous Okrug - Ugra for the five-year period 2015-2019.

\section{Analysis of the results}

The Sustainable ecological development diagram of the Khanty-Mansi Autonomous District-Yugra is shown in Figure 2.

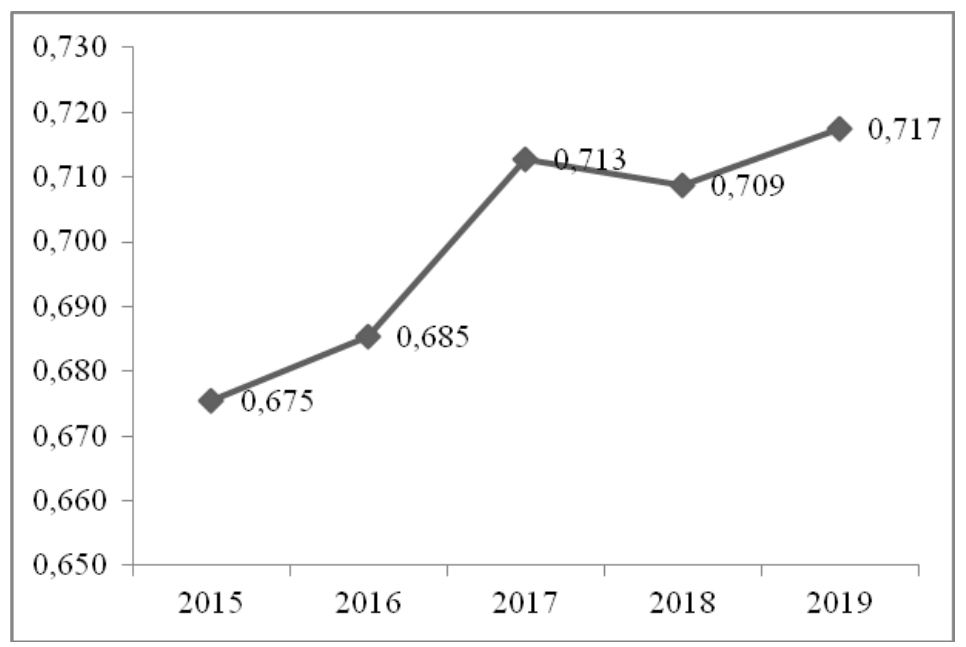

Fig. 2. Sustainable ecological development of the Khanty-Mansi Autonomous District -Yugra 
The diagram represents the trend of ISDecol over a period of 5 years and shows a steady growth of indicators. The district has made progress mainly by reducing $\mathrm{CO} 2$ emissions.

The diagram of sustainable economic development of the Khanty-Mansi Autonomous District -Yugra is shown in Figure 3.

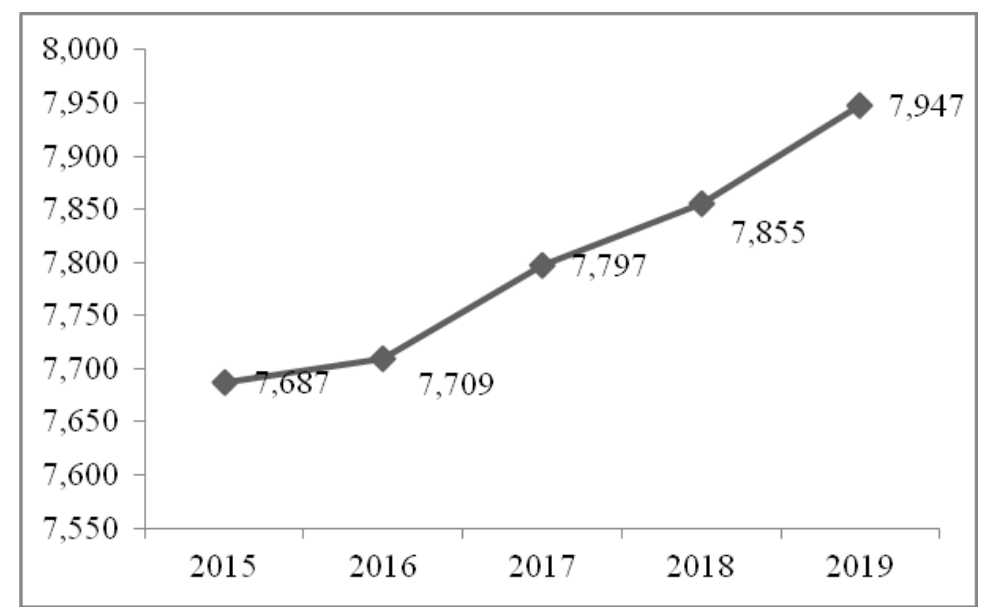

Fig. 3. Sustainable economic development of the Khanty-Mansi Autonomous District-Yugra

The diagram represents the ISDecon trend over a period of 5 years and shows a steady increase in indicators. The economic development of the district was successful mainly due to an increase in the investment component.

Next, we will determine the closeness of the interconnection between the two indices, for this two types of correlation are used: Spearman's rank correlation coefficient and the correlation coefficient of the moment of Pearson's product.

Spearman's formula gives the correlation coefficient between two random variables, which are assigned a rank. It estimates the dependence between two variables, expressed by a monotonic function (i.e., with the growth of one variable, the second increases, and vice versa). Spearman's ideal correlation occurs when each of the variables is an ideal monotonic function of the other [13].

$$
\rho={\frac{6 \Sigma D}{n\left(n^{2}-1\right)}}^{2}
$$

Carl Pearson, an English mathematician, one of the founders of biometrics, proposed a method for determining a linear relationship between two variables. This is a widely used method and it is known as the Pearson correlation coefficient (r) [14].

$$
r=\frac{\operatorname{cov}(x, y)}{\sigma x \times \sigma y}
$$

The results of calculating the two correlation coefficients are presented in Table 1 and Table 2 .

Table 1. Spearman's correlation coefficient.

\begin{tabular}{|c|c|c|}
\hline Rank & Rank 1 & Rank 2 \\
\hline Rank 1 & 1 & \\
\hline Rank 2 & 1 & 1 \\
\hline
\end{tabular}


Table 2. Pearson's correlation coefficient.

\begin{tabular}{|l|c|c|}
\hline \multicolumn{1}{|c|}{ ISD } & ISDecon & ISDecol \\
\hline ISDecon & 1 & \\
\hline ISDecol & 0,90 & 1 \\
\hline
\end{tabular}

Both tables prove the existence of a strong positive correlation between the ecological and economic development of the Khanty-Mansiysk Autonomous District -Yugra. The obtained result shows that the district is socially oriented and pays great attention to the preservation of the natural environment, which is important for the indigenous peoples of the North.

The purpose of the study was to identify the link between environmental and economic performance. Such a interconnection has been identified, which suggests that the district has achieved good results in the area of sustainable development. Thus, the results obtained on the basis of the proposed model of the correlation of the components of sustainable ecological and economic development of the region made it possible to identify the interconnection between the components of sustainable development.

There are other correlation methods that allow you to identify the interconnection between variables, such as the Granger causality test, designed to test the causal interconnection between time series. Granger's test is used to determine if one variable can be predicted using another [15], [16]. But to calculate additional correlation methods, more historical data are required, in addition, other statistical issues such as heteroscedasticity, autocorrelation may arise.

\section{Conclusions}

1. The main objective of sustainable development is to harmonize economic, environmental and social development. Achieving sustainable development can be complicated by the impacts of climate change. In terms of absolute $\mathrm{CO} 2$ emissions, Russia ranks fourth after China, the USA and India, in terms of per capita emissions, it ranks second after the United States.

2. For the northern territories, taking into account the specifics of northern ecosystems, the main blow of the consequences of climate change will be on biological resources. Bioresources are the main source of food supply for indigenous peoples, therefore they are among the first to feel the effects of climate change and play an important role in monitoring the environmental situation in their places of traditional residence and in the surrounding areas. In this way, indigenous peoples are becoming an important link in the implementation of the Sustainable Development Goals in the face of climate change.

3. To determine the degree of achievement of sustainable development, a correlation model was developed. The calculation of the correlation model proves the existence of a interconnection between economic development and the ecological state of the KhantyMansi Autonomous District-Yugra. The results showed a strong positive interconnection between the two components of sustainability in the development of the region under study. However, no significant negative impact of climate change has been identified. This is probably due to the presence of huge areas of biological resources capable of absorbing $\mathrm{CO} 2$. Statistics on $\mathrm{CO} 2$ uptake by forests are not kept. This suggests a «flattening» of the carbon footprint, which is not reflected in the statistics. This can explain the minimal negative impact of climate change on the studied environmental indicators of the region.

4. The results obtained through the correlation model can be used in regional management to assess the current situation, to identify the interconnection between the components of sustainable development for indigenous peoples. Also, the presented model 
can be useful in developing a regional development strategy in the aspect of achieving sustainable development.

\section{References}

1. A.I. Tatarkin, R-Economy, 1, 1 (2016)

2. K. N. Kikkas, MIR (Modernization. Innovation. Development), 4, 142 (2016)

3. E.V. Maryin, Issues of Sustainable Development of Society, 2, 418 (2020)

4. U. Ayres, A. Kneese, Production, American Economic Review, 59, 282 (2009)

5. K. Lakkala et al., Earth Syst. Sci. Data 2020, 12, 947 (2020)

6. T. P. Doran \& M. K. Zimmerman, EOS Transaction American Geophysical Union, 3, 22 (2009)

7. S. Fankhauser, Environmental and Development Economics, 3, 369 (2008)

8. T. Wiedmann, Economic Systems Research, 21, 175 (2009)

9. J. Munksgaard, K. A. Pedersen, Energy Policy, 29, 327 (2011)

10. N. N. Ilysheva et al., Discussion, 6, 23 (2019)

11. N. N. Ilysheva et al., Montenegrin Journal of Economy, 4, 19 (2017)

12. S. P. Zemtsov, V. L. Baburin, Economy of the region, 1, 117 (2016)

13. T. W. Anderson, S. L. Sclove, Introductory Statistical Analysis (Houghton Mifflin Company). Boston, Houghton Mifflin, 82 (2005)

14. H. Moed, Journal of the American Society for Information Science and Technology, 10, $1088(2005)$

15. S. Das Gupta, Journal of Multivariate Analysis, 7, 82 (2007)

16. S. Miri, Life Science Journal, 10, 1255 (2013) 